\title{
Role of ankle foot orthosis in improving locomotion and functional recovery in patients with stroke: A prospective rehabilitation study
}

\author{
H. Sankaranarayan ${ }^{1}$, Anupam Gupta ${ }^{1}$, Meeka Khanna ${ }^{1}$, Arun B. Taly ${ }^{1,2}$, K. Thennarasu ${ }^{3}$ \\ Departments of ${ }^{1}$ Neurological Rehabilitation, ${ }^{2}$ Neurology and ${ }^{3}$ Biostatistics, National Institute of Mental Health and Neuro Sciences, Bengaluru, \\ Karnataka, India
}

\begin{abstract}
Objective: To study role of ankle foot orthosis (AFO) in improving locomotion and functional recovery after stroke. Setting: Neurological Rehabilitation Department of a university research tertiary hospital. Patients and Methods: AFO and activity based rehabilitation. Main Outcome Measures: Distance (meters) covered during the 6-minute walk test (6MWT) and speed (meter/second) during the 10-meter walk test. Functional abilities assessed using Functional Independence Measure (FIM ${ }^{\circ}$. Results: Twenty-six patients (21 male) with stroke (mean duration 196.7 days, range 45-36o days) and mean age of 41.6 years (range 18-65 years, standard deviation [SD] 12.5) were included. Fourteen had right hemiplegia. The mean length of stay in the unit was 26.5 days (range 18-45 days, SD 5.5). All patients had equinus deformity with spastic foot drop and were provided with AFO. Walking endurance with 6MWT was $90 \mathrm{~m}$ on admission (without AFO). At discharge, it improved to $174 \mathrm{~m}$ with AFO and $121 \mathrm{~m}$ without AFOs $(P<0.001$-with and without AFO at discharge). Walking speed improved from $0.4 \mathrm{~m} / \mathrm{s}$ (admission) to $0.51 \mathrm{~m} / \mathrm{s}$ with AFO, $P=0.004$ and $0.45 \mathrm{~m} / \mathrm{s}$ without $\mathrm{AFO}, P=0.015)$ at discharge. Nine patients $(34.6 \%)$ had clinically important difference-minimal clinically important difference ( $>0.16 \mathrm{~m} / \mathrm{s}$ speed gain; $>50 \mathrm{~m}$ endurance gain) at discharge. The mean FIM score on admission was $84.3 \pm 18.6$. At discharge FIM ${ }^{\circ}$ improved to 101.9 $\pm 13.7(P<0.001)$. Conclusions: Use of AFOs improve gait parameters significantly in only one-third stroke patients in the study when combined with activity-based inpatient-rehabilitation.
\end{abstract}

Key words: Ankle foot orthosis, inpatient rehabilitation, stroke, walking endurance, walking speed

\section{Introduction}

Restoration of locomotion is one of the main goals of stroke rehabilitation. ${ }^{[1]}$ Ability to walk following a stroke is often impaired due to muscle weakness, spasticity, compromised sensory-motor control and/or impaired cognitive functions. ${ }^{[2,3]}$ Stroke survivors with hemiparesis show a relatively shorter step length, a longer stance phase, and a shorter swing phase of the affected side. ${ }^{[4]}$

\section{Address for correspondence:}

Dr. Anupam Gupta, Department of Neurological Rehabilitation,

National Institute of Mental Health and Neuro Sciences,

Bengaluru - 560 029, Karnataka, India.

E-mail: drgupta159@yahoo.co.in

\begin{tabular}{|l|l|}
\hline \multicolumn{2}{|c|}{ Access this article online } \\
\hline Quick Response Code: & Website: \\
\hline & www.ruralneuropractice.com \\
\hline & \\
\hline
\end{tabular}

Spastic equinus is one of the most common gait problems in persons with stroke. This is usually related to spasticity of triceps surae or contracture of this muscle or tendon, resulting in reduced ankle dorsiflexion both during stance and swing phases. Equinovarus foot shifts the weight support of the heel to the lateral plantar surface of the foot, and may cause a loss of balance and a reduction in stride security. Ankle foot orthoses (AFO) are prescribed to facilitate ankle control in cases of equinus and/or varus foot, ${ }^{[5]}$ provide mediolateral stability of the ankle in the stance phase, facilitate gait in the swing phase, and reduce energy expenditure while walking. ${ }^{[6]}$ Some researchers hold the view that an

This is an open access article distributed under the terms of the Creative Commons Attribution-NonCommercial-ShareAlike 3.0 License, which allows others to remix, tweak, and build upon the work non-commercially, as long as the author is credited and the new creations are licensed under the identical terms.

For reprints contact: reprints@medknow.com

How to cite this article: Sankaranarayan H, Gupta A, Khanna M, Taly $A B$, Thennarasu $K$. Role of ankle foot orthosis in improving locomotion and functional recovery in patients with stroke: A prospective rehabilitation study. J Neurosci Rural Pract 2016;7:544-9. 
AFO can prolong dependence on a mechanical device, leading to an increase in muscle disuse, especially the dorsiflexors of the ankle, with a consequent delay in functional recovery. ${ }^{[4]}$

Apart from orthosis, relatively newer approaches involving body weight support (electromechanical/ robot-assisted), functional electrical stimulation-based orthosis, rhythmic auditory stimulation, and virtual reality have been tried along with the conventional rehabilitation strategies to restore locomotion in stroke survivors. ${ }^{[7-9]}$ Questions have been raised regarding the long-term safety, clinical effect, and cost-benefit of many of these interventions. ${ }^{[10]}$ Conventional gait training using an eclectic approach (involving therapeutic exercises, AFO, and task specific training) coupled with anti-spasticity measures (medications, chemo-denervation, and exercises) and gait aids continues to be more popular method in most centers.

Botulinum Toxin A, a neurotoxin on local injection in the spastic muscle, reduces tone, increases the range of motion and causes dose-dependent reversible paralysis in the muscle. ${ }^{[11]}$ Studies in the past with this toxin have shown no adverse effect and the tendency of improvement in spasticity in the injected muscles in stroke patients, which results in better gait. ${ }^{[12,13]}$

Rehabilitation medical specialists generally resort to an AFO along with other measures to tackle this equinus foot in stroke. Previous studies have pointed out their benefits on the gait parameters. ${ }^{[14,15]}$ However, many aspects regarding their efficacy remain unclear.

The primary objectives of this study were to study the effect of AFO supplemented with multidisciplinary inpatient stroke rehabilitation program on 2 clinical gait parameters - walking speed and endurance. The secondary objective was to determine if there was any improvement in their mobility related functional outcomes-motor Functional Independence Measure $\left(\mathrm{FIM}^{\circledR}\right) \cdot{ }^{[16]}$

\section{Patients and Methods}

This prospective study was conducted in the Department of Neurological Rehabilitation of a university tertiary care research hospital between December 2014 and May 2015. Participants were recruited through the outpatient service of the department and all stroke survivors attending the outpatient clinics were screened. Those fulfilling the inclusion criteria and willing to participate were included in the study. Overall 429 stroke survivors were screened during this period.

\section{Inclusion criteria}

1. Stroke survivors (men and women aged 18-65) admitted with a diagnosis of first arterial Stroke (due to cerebrovascular accident) with right or left hemiplegia

2. Spastic equinovarus foot with dynamic deformity requiring an $\mathrm{AFO}$

3. At least 6 weeks post-stroke but not more than 1 year duration

4. Good comprehension with an intact ability to follow threestep commands

5. Admission in Neurological Rehabilitation ward for at least 2 weeks (14 sessions) for activity based rehabilitation.

\section{Exclusion criteria}

1. Patient not fit to participate in rehabilitation program

2. Myocardial infarction in the last 6 months

3. Patients with unstable angina

4. Patients with global aphasia

5. Patients with recurrent strokes, bilateral hemispheric, cerebellar, or brain stem lesions

6. Patients with significant visual field deficits and orthopedic problems affecting participation and

7. Hemiplegia not due to cerebrovascular accident.

The protocol was approved by the Institute Ethics Committee, and informed consent was obtained from all the stroke survivors before study participation.

\section{Rehabilitation management}

- All the participants were provided with an AFO (polypropylene solid AFO; custom made by orthotist) within 5 days of admission to the ward

- A tripod cane was prescribed, based on the clinical assessment

- Activity-based therapy was provided consisting of lower limb strengthening with resistive exercises, treadmill training, spasticity reducing exercises, reaching in sitting and standing, balance and gait training (with $\mathrm{AFO}$ and gait aids), stair ascent and descent, functional abilities, and activities of daily living training. Training was conducted for a minimum of 14 sessions with at least 9 sessions after receiving AFOs $(120 \mathrm{~min} /$ day, 6 days/week for more than 2 weeks)

- Conventional inpatient rehabilitation, addressing other issues such as aphasia, cognitive and 
psychosocial issues, and optimization of medical comorbidities including pharmacotherapy was provided

- Patients assessed initially within $48 \mathrm{~h}$ of admission and subsequently $48 \mathrm{~h}$ before discharge from inpatient rehabilitation.

\section{Statistical analysis}

Variables were tested for normality of data by Shapiro-Wilk test and found to be not normal. Hence, the median was used to describe data and nonparametric Wilcoxon signed rank test was used to compare the change from admission to discharge. Statistical package for social science SPSS version 22.0 (IBM, IL, Chicago, USA) was used for analysis. Statistical significance was considered at $P<0.05$.

\section{Outcome measures}

\section{6-minute walk test}

Functional walk test such as the 6-minute walk test (6MWT) is often used to determine functional capacity in individuals with compromised ability. ${ }^{[17,18]}$ We adhered to the ATS standards ${ }^{[19]}$ for the walkway length, course layout, and location the participant was asked to walk continuously in a marked $30 \mathrm{~m}$ hallway of a $50 \mathrm{~m}$ long, flat, straight enclosed corridor adjacent to the ward. The distance walked in 6 min was recorded at admission and with and without AFOs at discharge. As suggested by Dunn et al., ${ }^{[20]}$ we used their checklist for reporting the 6MWT. Baseline (admission) walk test was done without AFO or physical assistance. Only 8 participants needed a tripod cane. All participants were made to walk with and without $\mathrm{AFO}$ at the time of discharge. Adequate rest was given between the two tests. Walking aids were generally avoided, $8(30 \%)$ participants were unable to walk without the tripod cane at admission, and they continued to require the tripod cane at discharge.

\section{0-meter walk test}

Walking speed was measured in meters per second as the participant walked across a $10 \mathrm{~m}$ walkway. ${ }^{[21]}$ The participants were given standard instruction and asked to walk at their preferred pace. Baseline (admission) test was done without any aid (except for eight participants who used the tripod cane). Discharge test was done with and without AFO and eight used the tripod cane. The average of three trials was taken as the walking speed at each assessment for all participants.

\section{Functional independence measure ${ }^{916]}$}

The FIM ${ }^{\circledR}$ is composed of 18 items divided into 6 levels (minimum score 18; maximum score, equivalent to total functional independence: 126) (16). Each item envisages 7 levels of performance independence $(7$, total independence and 1 , total dependence or un-assessable).
The FIM $^{\circledR}$ can be subdivided into a 13-item motor subscale $\left(\right.$ motor FIM ${ }^{\circledR}$ ) and a 5-item cognitive subscale (cog FIM $\left.{ }^{\circledR}\right)$. The scoring ranges for the motor and cognitive subscales are 13-91 and 5-35, respectively. The license for using FIM $^{\circledR}$ instrument was obtained from UDSMR (Uniform Data System for Medical Rehabilitation, New York).

\section{Scandinavian stroke scale}

Impairment after stroke was assessed using Scandinavian Stroke Scale (SSS). It consists of eight parameters, including consciousness, cognitive deficits, motor power, and walking ability, on a graded score of $0-12$. The maximum score is 58; higher scores indicate better outcome.

\section{Results}

Thirty participants fulfilled the inclusion criteria and were recruited in the study. By the time of discharge, 4 patients showed good motor recovery in ankle dorsifexors of the affected limb and did not require AFO for locomotion. These patients were excluded from the final analysis. Data of 26 participants (21 men and 5 women) were included. 14 participants were affected on the right whereas 12 were affected on the left side. All 26 were able to complete the walk tests, and there was no adverse event. All were provided a solid polypropylene AFO and received minimum 14 sessions of activity-based rehabilitation including gait training (one session per day). Patients were encouraged to use a splint at other times of the day also especially while walking. Seventeen $(65 \%)$ patients had an ischemic stroke, and $9(35 \%)$ had hemorrhagic stroke. All involved the anterior cerebral circulation (MCA/ACA territory). Nineteen (73\%) out of 26 patients had moderate to severe stroke with SSS scores $<40$. Mean length of stay in the unit was 26.5 days (range 18-45 days, standard deviation 5.5).

The mean walking speed of the stroke survivors on admission was $0.4 \mathrm{~m} / \mathrm{s}$. The walking speed improved with AFOs. The mean walking speed at discharge was $0.51 \mathrm{~m} / \mathrm{s}$ with AFOs $(P=0.004)$ and $0.45 \mathrm{~m} / \mathrm{s}$ without $\operatorname{AFOs}(P=0.015)$.

The mean walking endurance (6MWT) of the stroke survivors on admission was $127.6 \mathrm{~m}$. The walking speed improved with AFOs. The mean walking endurance (6MWT) at discharge was $172.2 \mathrm{~m}$ with AFOs and $146.8 \mathrm{~m}$ without AFOs. The improvement at discharge both with and without AFO was statistically significant $(P<0.001)$.

Significant function recovery (using FIM) was observed with inpatient rehabilitation. Still only 4 (15\%) of them 
had an FIM $^{\circledR}$ score > 115 at discharge (more or less fully independent) [Table 1].

Walking speed categories of patients at discharge are mentioned in Table 2.

\section{Discussion}

The impaired locomotion after stroke has been a key area of research among neurological disorders ${ }^{[22]}$ and several strategies have been devised to restore the walking ability of stroke survivors. Our study focused on analyzing role and benefits of the AFO in improving gait parameters (walking speed and endurance) in stroke survivors. An earlier study in the same setup has shown feasibility to conduct task-specific locomotor training programs for chronic stroke survivors with moderate disabilities. ${ }^{[23]} \mathrm{In}$ this study, we utilized the same principle and imparted the conventional gait rehabilitation and assessed the effect of AFO on mobility-related functional outcomes.

\section{Impact of inpatient rehabilitation}

The fact that all the 26 participants were rehabilitation naive and never exposed to any sort of rehabilitation since the stroke stands testament to the role of stroke

Table 1: Functional score at admission and discharge

\begin{tabular}{|c|c|c|c|c|}
\hline & & Admission & Discharge & $\begin{array}{c}P \text { value } \\
\text { (wilcoxon } \\
\text { signed } \\
\text { ranks test) }\end{array}$ \\
\hline $\begin{array}{l}\text { MAS plantar flexors } \\
\text { (modified ashworths' } \\
\text { scale) }\end{array}$ & $n=26$ & $1+$ & 1 & 0.822 \\
\hline $\begin{array}{l}\text { Total FIM }{ }^{\circledR} \text { (functional } \\
\text { independence measure) }\end{array}$ & $n=26$ & $84.3 \pm 18.6$ & $101.8 \pm 13.7$ & $<0.001$ \\
\hline $\begin{array}{l}\text { Mobility } \mathrm{FIM}^{\circledR} \text { (functional } \\
\text { independence measure) }\end{array}$ & $n=26$ & $18.9 \pm 6.6$ & $26.0 \pm 4.7$ & $<0.001$ \\
\hline $\begin{array}{l}\text { Motor } \mathrm{FIM}^{\circledR} \text { (functional } \\
\text { independence measure) }\end{array}$ & $n=26$ & $54.1 \pm 14.1$ & $70.1 \pm 9.9$ & $<0.001$ \\
\hline $\begin{array}{l}\text { Cog } \mathrm{FIM}^{\circledast} \text { (functional } \\
\text { independence measure) }\end{array}$ & $n=26$ & $30.3 \pm 6.6$ & $31.7 \pm 4.9$ & 0.007 \\
\hline
\end{tabular}

Table 2: Walking speed categories at discharge based on stroke severity

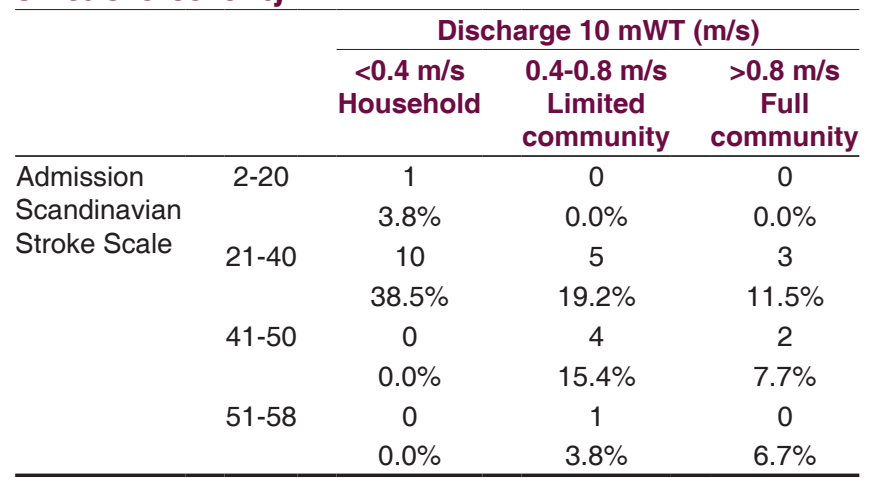

rehabilitation in effecting a significant change in the functional ambulation in these stroke survivors [Table 1]. A reduction in gait velocity is common among stroke victims. Mean gait velocity of healthy individuals is around $1.3 \mathrm{~m} / \mathrm{s}$ but ranges from 0.23 to $0.73 \mathrm{~m} / \mathrm{s}$ among individuals with hemiparesis. ${ }^{[22]}$ The results from this study also suggest the same with mean walking speed of the group increased from $0.40 \mathrm{~m} / \mathrm{s}$ to $0.51 \mathrm{~m} / \mathrm{s}$ (without $\mathrm{AFO})$ at the end of rehabilitation.

According to Schmid et al. ${ }^{[24]}$ when $10 \mathrm{~m}$ gait velocity measures are stratified into clinically meaningful functional ambulation classes such as household ambulation $(\leq 0.4 \mathrm{~m} / \mathrm{s})$, limited community ambulation $(0.4-0.8 \mathrm{~m} / \mathrm{s})$, and full community ambulation $(\geq 0.8 \mathrm{~m} / \mathrm{s})$, changes in $10 \mathrm{~m}$ gait velocity are clinically meaningful. Transitioning to a higher class of ambulation is associated with substantially better functional independence and quality of life, especially with regard to mobility and community participation, in initial household ambulators. In the current study, only $5(19.2 \%)$ advanced to limited community ambulation $(0.4-0.8 \mathrm{~m} / \mathrm{s})$ and $1(3.8 \%)$ to full community ambulation $(0.8 \mathrm{~m} / \mathrm{s})$. It is noteworthy that $11(42.3 \%)$ of the stroke survivors in the household ambulation $(<0.4 \mathrm{~m} / \mathrm{s})$ on admission had a moderate-severe stroke (SSS $<40$ ), and did not make the transition to a higher class.

Pohl et al. reported that the demographic data that can be used to predict the distance healthy adults can walk in 6 min cannot predict the distance achieved by adults with stroke. The performance in the 6MWT for stroke survivors is influenced by the motor impairment of the affected lower limb and balance. ${ }^{[25]}$ Not surprisingly, our study showed similar results. Eight (30.7\%) of the stroke survivors who walked $<100 \mathrm{~m}$ in $6 \mathrm{~min}$ had a moderate to severe stroke $(\mathrm{SSS}<40)$.

\section{Role of ankle foot orthosis}

An AFO seems to exert a positive influence on the joint alignment of the affected lower limb, with improvements in cadence and gait velocity. While these variables alone do not represent improved gait stability, the analysis of such aspects allows a better practical understanding of the effects of physical therapy and improvements in the motor skills of stroke survivors. ${ }^{[26]}$ In the majority of studies, the use of a rigid or articulated AFO offered important benefits with regard to gait velocity of stroke patients, regardless of the material with which the device was made.

Minimal clinically important difference (MCID) of greater than $0.16 \mathrm{~m} / \mathrm{s}^{[27]}$ gain in walking speed was noted in $8(30.7 \%)$ of the participants when they used the AFO, 
whereas only $2(8 \%)$ of among then had the same gain without the AFO at the time of discharge. It has been shown that higher gait speeds associated with improved function poststroke, ${ }^{[28]}$ and reduced mortality in older adults ${ }^{[29]}$ and use of an AFO, improves the walking speed.

The MCID in the 6MWT for stroke has been estimated to be $50 \mathrm{~m}$. Only 9 (34.6\%) of the participants had an improvement of $50 \mathrm{~m}$ or more at the time of discharge while using the AFO. Without the AFO, only 3 (11.5\%) showed an MCID, even though all participants improved in the walking speed and endurance while using the $\mathrm{AFO}$, at the time of discharge. However, all participants reported subjective improvement and preferred to walk with the AFO citing that they felt better, and that speed was more with AFOs. Dogan et al. have also reported similar subjective changes with AFO use in stroke survivors in their study. ${ }^{[30]}$

The duration since the stroke, initial $\mathrm{FIM}^{\circledR}$, admission walking speed 10-meter walk test and endurance (6MWT) and ankle plantar flexor spasticity correlated with change in $\operatorname{FIM}^{\circledast}(P<0.001)$ in this study.

The limitations of this study include a very small sample size, lack of control group, and randomization for the interventions done. Two-third of the participants was given oral anti-spasticity medication, which also would have contributed to the gait improvement by reducing the spasticity and thus could be a confounder. The participants got only 2 weeks to get familiar with AFO use and the acceptance and compliance varied among the participants. This could be a reason why only $34.6 \%$ had an MCID in the gait parameters at discharge. The time between 6MWT tests with and without AFO (at discharge) was not standardized for each participant. However, adequate rest was provided to minimize any effect of fatigue.

\section{Conclusions}

The effect of AFO on gait parameters such as walking speed and endurance was mixed in the study with more than two-third showed no significant effect and the study also underscores the need for referral to an inpatient rehabilitation facility post stroke for improving ambulation.

\section{Financial support and sponsorship}

Nil.

\section{Conflicts of interest}

There are no conflicts of interest.

\section{References}

1. Eng JJ, Tang PF. Gait training strategies to optimize walking ability in people with stroke: A synthesis of the evidence. Expert Rev Neurother 2007;7:1417-36.

2. Ferreira LA, Neto HP, Grecco LA, Christovão TC, Duarte NA, Lazzari RD, et al. Effect of ankle-foot orthosis on gait velocity and cadence of stroke patients: A systematic review. J Phys Ther Sci 2013;25:1503-8.

3. de Wit DC, Buurke JH, Nijlant JM, Ijzerman MJ, Hermens HJ. The effect of an ankle-foot orthosis on walking ability in chronic stroke patients: A randomized controlled trial. Clin Rehabil 2004;18:550-7.

4. Leung J, Moseley AM. Impact of ankle-foot orthoses on gait and leg muscle activity in adults with hemiplegia. Physiotherapy 2003;89:39-60.

5. Chen CC, Hong WH, Wang CM, Chen CK, Wu KP, Kang CF, et al. Kinematic features of rear-foot motion using anterior and posterior ankle-foot orthoses in stroke patients with hemiplegic gait. Arch Phys Med Rehabil 2010;91:1862-8.

6. Bregman DJ, Harlaar J, Meskers CG, de Groot V. Spring-like Ankle Foot Orthoses reduce the energy cost of walking by taking over ankle work. Gait Posture 2012;35:148-53.

7. Dobkin BH, Dorsch A. New evidence for therapies in stroke rehabilitation topical collection on cardiovascular disease and stroke. Curr Atheroscler Rep 2013;15:331.

8. Laver KE, George S, Thomas S, Deutsch JE, Crotty M. Virtual reality for stroke rehabilitation. Cochrane Database Syst Rev 2015;2:CD008349.

9. Suh JH, Han SJ, Jeon SY, Kim HJ, Lee JE, Yoon TS, et al. Effect of rhythmic auditory stimulation on gait and balance in hemiplegic stroke patients. NeuroRehabilitation 2014;34:193-9.

10. Brewer L, Horgan F, Hickey A, Williams D. Stroke rehabilitation: Recent advances and future therapies. QJM 2013;106:11-25.

11. Parratte B, Tatu L, Vuillier F, Diop M, Monnier G. Intramuscular distribution of nerves in the human triceps surae muscle: Anatomical bases for treatment of spastic drop foot with botulinum toxin. Surg Radiol Anat 2002;24:91-6.

12. Demetrios M, Khan F, Turner-Stokes L, Brand C, McSweeney S. Multidisciplinary rehabilitation following botulinum toxin and other focal intramuscular treatment for post-stroke spasticity. Cochrane Database Syst Rev 2013;6:CD009689.

13. Kaji R, Osako Y, Suyama K, Maeda T, Uechi Y, Iwasaki M; GSK Spasticity Study Group. Botulinum toxin type A in post-stroke lower limb spasticity: A multicenter, double-blind, placebo-controlled trial. J Neurol 2010;257:1330-7.

14. Nolan KJ, Savalia KK, Lequerica AH, Elovic EP. Objective assessment of functional ambulation in adults with hemiplegia using ankle foot orthotics after stroke. PM R 2009;1:524-9.

15. Cioni M, Esquenazi A, Hirai B. Effects of botulinum toxin-A on gait velocity, step length, and base of support of patients with dynamic equinovarus foot. Am J Phys Med Rehabil 2006;85:600-6.

16. Uniform Data System for Medical Rehabilitation. Buffalo (NY): University of Buffalo. Available from: http://www.udsmr.org/.[Last cited on 2014 Dec 07].

17. Kim M, Stroke H, Journals PN. Functional walk test in individuals with stroke: Relation to perceived exer. Nursing (Lond);1:4-5.

18. Kosak M, Smith T. Comparison of the 2-, 6-, and 12-minute walk tests in patients with stroke. J Rehabil Res Dev 2005;42:103-7.

19. Crapo RO, Casaburi R, Coates AL, Enright PL, MacIntyre NR, McKay RT, et al. ATS statement: Guidelines for the six-minute walk test. Am J Respir Crit Care Med 2002;166:111-7.

20. Dunn A, Marsden DL, Nugent E, Van Vliet P, Spratt NJ, Attia J, et al. Protocol variations and six-minute walk test performance in stroke survivors: A systematic review with meta-analysis. Stroke Res Treat 2015;2015:484813.

21. Perry J, Garrett M, Gronley JK, Mulroy SJ. Classification of walking handicap in the stroke population. Stroke 1995;26:982-9.

22. Verma R, Arya KN, Sharma P, Garg RK. Understanding gait control in post-stroke: Implications for management. J Bodyw Mov Ther 2012;16:14-21.

23. Srivastava A, Taly AB, Gupta A, Murali T. Rehabilitation interventions to improve locomotor outcome in chronic stroke survivors : A prospective, 
repeated - Measure study. Neurol India 2015;63:347-52

24. Schmid A, Duncan PW, Studenski S, Lai SM, Richards L, Perera S, et al. Improvements in speed-based gait classifications are meaningful. Stroke 2007;38:2096-100.

25. Pohl PS, Duncan PW, Perera S, Liu W, Lai SM, Studenski S, et al. Influence of stroke-related impairments on performance in 6-minute walk test. J Rehabil Res Dev 2002;39:439-44.

26. Guerra Padilla M, Molina Rueda F, Alguacil Diego IM. Effect of ankle-foot orthosis on postural control after stroke: A systematic review. Neurologia 2014;29:423-32.

27. Tilson JK, Sullivan KJ, Cen SY, Rose DK, Koradia CH, Azen SP, et al.
Meaningful gait speed improvement during the first 60 days poststroke: Minimal clinically important difference. Phys Ther 2010;90:196-208.

28. Hardy SE, Perera S, Roumani YF, Chandler JM, Studenski SA. Improvement in usual gait speed predicts better survival in older adults. J Am Geriatr Soc 2007;55:1727-34.

29. Perera S, Mody SH, Woodman RC, Studenski SA. Meaningful change and responsiveness in common physical performance measures in older adults. J Am Geriatr Soc 2006;54:743-9.

30. Dogan A, Mengüllüoglu M, Özgirgin N. Evaluation of the effect of ankle-foot orthosis use on balance and mobility in hemiparetic stroke patients. Disabil Rehabil 2011;33:1433-9. 